\title{
CONTRATO: ESTRUTURA MILENAR DE FUNDAÇÃO DO DIREITO PRIVADO.
}

\author{
Superando a crise e renovando princípios, no início do vigésimo primeiro século, ao \\ tempo da transição legislativa civil brasileira.
}

\author{
Giselda Maria Fernandes Novaes Hironaka \\ Professora Doutora do Departamento de Direito Civil da \\ Faculdade de Direito da Universidade de São Paulo.
}

Resumo:

A ingerência gradativa por parte do Estado na estruturação do conteúdo contratual. O parâmetro liberdade de contratar com liberdade contratual, cujo diagnóstico sempre foi pessimista a respeito da sobrevida do contrato. Como o "sonho de John Lenon", o contrato não morreu. Nem declinou, nem encolheu, nem perdeu espaço, nem poder.

\begin{abstract}
:
The gradual interference by the State in the structuration of the contractual's content. The parameter between the freedom to contract and contractual's freedom, which diagnosis has always been pessimist about the contract's overlive. Like "John Lennon's dream", the contracts didn't die. Neither declined, neither shrank, nor lost space or power.
\end{abstract}

Unitermos: liberdade de contratar; liberdade contratual; estrutura do contrato.

A segunda metade do século $\mathrm{XX}$, principalmente, foi o tempo em que mais se falou acerca de uma eventual decadência do contrato, tido sempre como um dos fundamentais pilares de sustentação do Direito Privado e da autonomia da vontade privada.

Sob o vaticínio da crise das instituições, a crise do contrato igualmente se desenhou e exprimiu-se debaixo da inegável limitação da autonomia privada, mormente em face da limitação à liberdade dos atores ou partícipes contratuais, no que respeita à outrora livre fixação do conteúdo das cláusulas de um contrato.

Uma ingerência cada vez mais presente, por parte do Estado, na estruturação desse conteúdo contratual, tendo em vista a salvaguarda de interesses

* Trabalho apresentado no 5 "Seminário de Estudos sobre o Novo Código Civil, promovido pela Escola Judicial Des. Edćsio Fcrnandes c pelo Tribunal de Justiça do Estado de Minas Gerais, cm Ubcrlândia, cm 23 de agosto de 2002. 
sociais mais significativos que a mera intenção e simples pretensão dos contratantes, constituiu-se, também, em forte razão para a crescente onda de descrédito que pretendeu tomar conta do destino do contrato enquanto tradicional e clássico instituto de Direito Privado.

Confundindo-se, muitas vezes, liberdade de contratar com liberdade contratual, o diagnóstico foi sempre muito pessimista, a respeito da sobrevida institucional do contrato. Mas, como o "sonho de John Lenon", o contrato não morreu. Nem declinou, nem encolheu, nem perdeu espaço, nem poder.

Rui de Alarcão' escreveu, e com toda a razão, que tal pessimismo foi claramente desmentido, a significar que o alarde foi exagerado e que a pós-modernidade prescreve a necessidade de novos modelos de realização do Direito, estando entre eles, certamente, os novos modelos contratuais que todos os dias se multiplicam, indicando uma fertilidade inesgotável desses paradigmas e o seu verdadeiro e sempre renovado papel de organizador e auto-regulamentador dos interesses privados.

Ora mais publicizado, ora mais socializado, ora mais poroso à intervenção estatal, ora mais limitado quanto ao seu conteúdo específico, ora mais funcionalizado, não importa. Todas essas faces são as faces do contrato, que se transmuda e evolui sempre, como a própria transmudação e evolução da pessoa humana e das relações que estabelece com os demais. A dinâmica própria da vida dos homens e a realidade jurídica subjacente conseguem explicar e justificar essa mobilidade, traçando-a naturalmente, conforme convém, e imprimindo o devido grau de certeza acerca da necessidade e urgência desta releitura contratual. Construção e crítica se alternaram, [desde o início do anterior século], produzindo um movimento de edificação de uma teoria [geral do Direito privado] tão sólida quanto volátil. ${ }^{2}$

Esse movimento é absolutamente saudável, rejuvenescedor e revigorante para as instituições privadas, mesmo porque, dizendo respeito a relações de natureza intersubjetiva, quer dizer, dos sujeitos entre si, essas instituições se renovam com o próprio uso, e o seu eventual desuso é que pode acarretar sua morte, por inércia. ${ }^{3}$

O contrato não caiu em desuso nunca e, por isso, permanece vivo; sua força revela sua indispensabilidade no trato das relações jurídicas e da mantença da segurança.

Mudam os fatos, mudam os homens, muda a realidade social, altera-se, por força da conseqüência, a arquitetura jurídica subjacente. Mas o contrato é sempre o contrato, afinal. Sob o paradigma simplesmente individualista da burguesia

1. Rui de Alarcão, Contrato, Democracia e Direito, in Revista Brasilcira de Dircito Comparado, n. 20, 1" scmestre de 200I, Rio de Janciro, 2001, pp. 03-12.

2. Andrć Lipp Pinto Basto Lupi, O Direito Privado Burguês, in www.cticadircito.hpg.ig.com.br/ artigos-pagc.htm

3. Intercssante c paradoxal, por exemplo, é o momento rico $\mathrm{cm}$ que a sociedade jurídica pode assistir ao ressuscitamento de um certo instituto privado, como o que vimos observando ocorrer justamente agora, com a proximidade da vigência do novo Código Civil Brasilciro que traz, $\mathrm{cm}$ scu bojo, o instituto da superficic, prestigiado pelos romanos, mas $\mathrm{cm}$ desuso há muito, entre nós, ausente por isso da legislação brasileira anterior. 
revolucionária francesa, ou sob o paradigma de consagração dos princípios contratuais como princípios próprios da ordem natural, ou sob o paradigma meramente dogmático de conformação do Direito com a lei, o contrato muda de feição e atende aos interesses jurídicos dos contratantes de cada época. Até que se mostre, a cada época, como insustentável ou deficiente, quando então ele se remoldura e busca sua readequação, para prosseguir como o que sempre fundamentalmente foi: um instrumento essencial da organização social.

O contrato, tal como houvera sido, antes, concebido no Código Francês de 1804 , conferia poder absoluto à vontade individual e à liberdade contratual. Tal poder podia fazer surgir todos os direitos atribuíveis ao sujeito emissor da vontade, independentemente da preocupação social gerada a indagar se estaria, ou não, ferindo o interesse jurídico dos demais. Os tempos eram os da busca compulsiva da certeza científica, o que deu azo à torrente positivista esvaziada de conteúdo axiológico e da idéia mais geral e abstrata de Justiça.

Não havia como prosperar indefinidamente uma visão assim fanática e tão apertada em seus próprios limites. Por isso, opôs-se o tempo de revisão do velho espírito revolucionário, dentro dos melhores limites da democracia e da Justiça dos rumores de superação dos ideais napoleônicos, para enfrentar a substituição de normas simplesmente supletórias por normas superiormente imperativas, na regulação dos contratos, de modo a se restringir a liberdade contratual (não a liberdade de contratar), pela adição de normas de ordem pública. Limitando-se a liberdade contratual, buscouse impedir a opressão do fraco pelo forte, do tolo pelo esperto, do pobre pelo rico.

A intervenção legislativa do Estado assim levada a cabo fez florescer um tempo novo, em que os maleficios do liberalismo jurídico foram mitigados pela proteção social que se estendeu ao economicamente mais fraco. As formas contratuais nas quais os direitos competiam todos a uma só das partes e as obrigações só à outra parte foram repelidas severamente pelo que se convencionou chamar dirigismo contratual. $^{4}$

Enfim, o que se deu neste interregno, desde a vitória burguesa até o paradigma da pós-modernidade, foi a sujeição da vontade dos contratantes ao interesse público, como se por atuação de um verdadeiro freio que moderasse a liberdade contratual, tudo em nome do interesse coletivo e em atenção às exigências do bem comum. O modelo atual pede e espera uma abertura maior do sistema outrora tão fechado a valorações externas e, para tanto, procura injetar-se de bases principiológicas novas ou, no máximo, renovadas.

Segundo o meu sentir, mais importa, hoje, identificar e reconhecer os princípios que regem a conformação contratual atual que continuar em debate acerca da presença ou da ausência dos novos tipos na composição positiva do Direito atual, mesmo porque o fato de estarem consagrados, ou não, pelo beneplácito do legislador

4. Conformc o capítulo denominado "A finç̧ão social do contrato", de lavra da autora deste cstudo, no livro Direito Civil - Estudos, Editora Del Rcy, Bclo Horizontc, 2000. 
contemporâneo, em sede codicista, não parece ser exatamente o viés de maior importância.

O novo Código Civil acolheu, em acréscimo ao modelo novecentista de Código Civil, os mesmos modelos contratuais até aqui atipicos, que já eram previsíveis desde a década de 70, quando o trabalho da Comisșão nomeada pelo Governo Federal, em 1969, sob a presidência de Sua Excelência, o Professor Miguel Reale, ganhou o status de Projeto de Lei (Projeto 634/75), quais sejam, o contrato de transporte, o contrato de comissão, o contrato de agência e distribuição, o contrato de corretagem, além do contrato preliminar e do contrato estimatório. Nada de novo ou surpreendente, enfim. Nada que a atipicidade contratual já não nos tivesse desenhado, à exaustão.

Nesse passo, levanto pedido de licença para registrar, desde logo, a inconveniência e o desacerto de se prosseguir, doutrinária e dogmaticamente, com aquela posição que sempre deu como sinônimas as expressões inominado e atípico. ${ }^{5}$ Sob nenhuma hipótese desconsidero tal crítica, eis que a atipicidade de um contrato não se traduz pelo fato de não ter ele, ou não, um nomem juris, senão pelo fato de não estar devidamente regulamentado em lei.

Reconhece-se com freqüência cada vez mais acentuada que contratos há que têm nome e nem por isso são nominados-tipicos já que, para que assim fossem considerados, estariam a exigir a presença de um regramento legislativo específico. Fico com a melhor e dominante doutrina para admitir que é preferível se referir, nestes casos, a contratos típicos e contratos atípicos, em lugar de nominados e inominados.

Assim, é contrato típico aquele que a lei regulamenta, estabelecendo regras específicas de tratamento e lhe concedendo um nomem juris. Aliás, penso que a denominação decorre da regulamentação, e não vice-versa, como poderia parecer se o adjetivo preferido fosse nominado.

A seu turno, portanto, contrato atípico é aquele não disciplinado pelo ordenamento jurídico, embora lícito, pelo fato de restar sujeito às normas gerais do contrato e pelo fato de não contrariar a lei, nem os bons costumes, nem os princípios gerais de Direito. Pouco importa se tem ou não um nome, porque este não é a característica da sua essência conceitual; seu traço característico próprio é o fato de não estar sujeito a uma disciplina própria.

Isso considerado, ainda que com a brevidade da premência do tempo, retomo o que mencionava antes, acerca de ter, o novo Código Civil, acolhido em seu bojo, e tipificado, portanto, modelos contratuais já em constância tradicional e antiga de uso no mundo do Direito, quais sejam e como já referido, o contrato de comissão, o contrato de transporte, o contrato de agência e distribuição, o contrato de corretagem.

De fora da nova Lei Civil permaneceram tipos mais contemporâneos, é certo, mas nem por isso exatamente novos, como o contrato de leasing e o contrato de franquia.

5. Já me referi a cssa inconveniência cm cstudo que resultou no capítulo denominado "Contratos atipicos e contratos coligados: caracteristicas fundamentais e dessemelhanças", no livro de minha autoria, supra rfcrido, Direito Civil - Estudos. 
O que o novo Código mesmo perdeu, como feliz oportunidade a ser considerada nesta ambiência mais definida dos modelos contratuais - como bem esclarece Junqueira de Azevedo - foi a oportunidade de estabelecer regras específicas para as modalidades coligadas de contratos, tão em evidência nos dias atuais, e que absolutamente não se confundem com os contratos mistos.

Se os contratos mistos são aqueles que resultam da combinação de elementos de diferentes contratos, formando uma espécie contratual não esquematizada em lei e se desta combinação de elementos de diferentes contratos, resulta uma unicidade que é o que, afinal, claramente os caracteriza, não há razão para se confundir os contratos mistos - assim definidos - com os contratos coligados, uma vez que, nestes, não se combinam elementos de vários contratos, simplesmente, mas o que se dá é a combinação de contratos completos. Por isso, nos contratos coligados há uma pluralidade de contratos, e a combinação deles não resulta, como nos contratos mistos, numa unicidade.

Contudo, e como adverte Orlando Gomes, o mecanismo da coligação muito se assemelha ao do contrato misto e, por isso mesmo, teria sido oportuno que o novo Código houvesse traçado as regras próprias de tratamento e tutela de tais contratos, impedindo a repetição da nefasta confusão entre eles e os contratos mistos.

Contrato coligado assim estampado, e segundo registra Maria Helena Diniz $^{6}$ é, então, o que apresenta celebração conjunta de duas ou mais relações contratuais, formando nova espécie de contrato não contemplado em lei. Na coligação, as figuras contratuais unir-se-ão em torno de relação negocial própria, sem perderem, contudo, sua autonomia, visto que se regem pelas normas alusivas ao seu tipo.

Por isso, são os seguintes os elementos constitutivos fundamentais dos contratos coligados: a. a celebração conjunta de dois ou mais contratos; b. a manutenção da autonomia de cada uma das modalidades que integra a modalidade nova; $c$. a dependência recíproca ou apenas unilateral dos contratos amalgamados; $d$. a ausência de unicidade entre os contratos jungidos; e. a sua regência jurídica pelas normas típicas alusivas a cada um dos contratos que se coligam.

Tive ocasião de iniciar um de meus estudos na área contratual, e sobre exatamente os contratos coligados, dizendo que 'sempre se mostrou confusa ou vacilante a doutrina, no sentido de bem situar no complexo quadro classificatório dos contratos, aqueles denominados simples e aqueles denominados mistos, aqueles denominados típicos e aqueles denominados atípicos e, por fim, aqueles denominados coligados, diferentes dos mistos, mas aparentados com os múltiplos'. Em conclusão, pautei minhas reflexões sobre o beneficio que haveria se a normativa contratual especificasse bem essa composição de tipos contratuais inteiros que se amalgamam, mas cuja regência se daria tipo a tipo, considerando a disfunção havida, em cada um dos contratos de per si.

Bem, o Código de 2002 não abriu espaço para essa regulamentação.

De qualquer forma, tudo quanto mais se coloca em pauta de discussão, nesse encontro de hoje, e segundo a seleção de assuntos que fiz, por julgar mais 
convenientes à alta consideração de vossas excelências, se referirá, daqui por diante, aos aspectos mais fundantes de toda a estrutura principiológica dos contratos, na nova visão que lhes determina o Código Civil de Miguel Reale.

Junqueira de Azevedo, em famosa palestra que proferiu no Seminário “O novo Código Civil - o que muda na vida do cidadão",.em 04 de junho deste ano de 2002, junto à Ouvidoria Parlamentar da Câmara dos Deputados, em Brasília, reconhece outros princípios contratuais, na legislação nova, que não estiveram explicitamente considerados pelo legislador do século passado, entre eles e principalmente, o principio da boa-fé objetiva e o princípio da função social do contrato. Ele refere que esta nova organização principiológica da Lei de 2002 não exclui os princípios clássicos do Direito Contratual, quer dizer, o principio da liberdade de contratar, o principio segundo o qual o contrato faz lei entre as partes (pacta sunt servanda ${ }^{7}$ ) e o principio da relatividade dos efeitos contratuais (res inter alios acta allis nec nocet prodest nec ${ }^{8}$ ). Ao contrário, a nova tábua de principios convive, completa e remoça a tábua tradicional, sem sufocá-la ou excluíla. Apenas convivem. $\mathrm{O}$ novo agrupamento principiológico revela, enfim, a feição contemporânea do contrato e seu traço de adaptação e coerência com a pessoa mais ética desta pós-modernidade, centro de todo o interesse epistemológico do Direito atual.

O contrato levado a efeito entre os atores contratuais contemporâneos, pois, passa a ser um contrato que exige mais do comprometimento ético e político de cada um desses partícipes, de modo a expandir projeção para muito além das fronteiras do mero sinalagma.

Ora, acerca desse novo contrato, então - instituto eternamente presente na triangulação básica do Direito Civil, ao lado da propriedade e da família - seria desejável referir, prioritariamente, às denominadas cláusulas gerais, que constituem uma técnica legislativa característica da segunda metade deste século, época na qual o modo de legislar casuisticamente, tão caro ao movimento codificatório do século passado - que queria a lei clara, uniforme e precisa [...] - foi radicalmente transformado, por forma a assumir a lei caracteristicas de concreção e individualidade que, até então, eram peculiares aos negócios privados. ${ }^{9}$

'A mais célebre das cláusulas gerais é exatamente a da boa-fé objetiva nos contratos. Mesmo levando-se em consideração o extenso rol de vantagens e de desvantagens que a presença de cláusulas gerais pode gerar num sistema de Direito, provavelmente a cláusula da boa-fé objetiva, nos contratos, seja mais útil que deficiente, uma vez que, por boa-fé, tout court, se entende que é um fato (que é psicológico) e uma virtude (que é moral)'

'Por força desta simbiose - fato e virtude - a boa-fé, numa visualização muito mais subjetiva, se apresenta como a conformidade dos atos e das palavras com

7. "Os pactos devem ser observados"

8. "O que é feito entre certas pessoas nem prejudica nem aproveita aoss outros".

9. Judith Martins-Costa, O Direito Privado como um sistema em construção:as cláusulas gerais no Projeto do Código Civil Brasileiro (www.jusnavigandi.com.br). 
a vida interior, ao mesmo tempo em que se revela como o amor ou o respeito à verdade. Contudo, observe-se, através da formidável lição de André Comte-Sponville, que a boa-fé não pode valer como certeza, sequer como verdade, já que ela exclui a mentira, não o erro' 10

O homem de boa-fé tanto diz o que acredita, mesmo que esteja enganado, como acredita no que diz. É por isso que a boa-fé é uma fé, no duplo sentido do termo. Vale dizer, é uma crença ao mesmo tempo que é uma fidelidade. $́$ crença fiel, e fidelidade no que se crê. É também o que se chama de sinceridade, ou veracidade, ou franqueza, é o contrário da mentira, da hipocrisia, da duplicidade, em suma, de todas as formas, privadas ou públicas, da má-fé. "

'Esta é a interessante visão da boa-fé pela sua angulação subjetiva; contudo, enquanto princípio informador da validade e eficácia contratual, a principiologia deve orientar-se pelo viés objetivo do conceito de boa-fé, pois visa garantir a estabilidade e a segurança dos negócios jurídicos, tutelando a justa expectativa do contraente que acredita e espera que a outra parte aja em conformidade com o avençado, cumprindo as obrigações assumidas. Trata-se de um parâmetro de caráter genérico, objetivo, em consonância com as tendências do Direito contratual contemporâneo, e que significa bem mais que simplesmente a alegação da ausência de má-fé, ou da ausência da intenção de prejudicar, mas que significa, antes, uma verdadeira ostentação de lealdade contratual, comportamento comum ao homem médio, o padrão jurídico standard'

'Em todas as fases contratuais deve estar presente o princípio vigilante do aperfeiçoamento do contrato, não apenas em seu patamar de existência, senão também em seus planos de validade e de eficácia. Quer dizer: a boa-fé deve se consagrar nas negociações que antecedem a conclusão do negócio, na sua execução, na produção continuada de seus efeitos, na sua conclusão e na sua interpretação. Deve prolongar-se até mesmo para depois de concluído o negócio contratual, se necessário'

Trata-se, portanto, da boa-fé objetiva entranhada no comportamento dos contratantes, capaz de exigir, deles, uma postura que sobrepassa a singela idéia de ser o contrato apenas uma auto-regulamentação de interesses contrapostos, um instrumento de composição de interesses privados antagônicos. O comportamento delineado pelo atributo da boa-fé objetiva é um comportamento tal que faz transcender a noção de colaboração entre os que contratam, antes de mais nada. E que os faz, por isso, mais leais, reciprocamente, mais informados, mais cuidadosos e mais solidários na persecução da finalidade contratual comum.

'Da consagração da boa-fé objetiva, nas relações contratuais - como pretendi demonstrar - decorrem principalmente os deveres de informação, de colaboração e de cuidado, somatória que realiza a insofismável verdade que, em sede

10. André Comte-Sponville, Pequeno Tratado das Grandes Virtudes, Martins Fontes, 1999, citado por Régis Fichtner Percira, “A responsabilidade civil pré-contratual”, Renovar, 2001.

II. Idem, ibdem. 
contratual, se lida com algo bem maior que o simples sinalagma, mas se lida com pressupostos imprescindiveis e socialmente recomendáveis, como a fidelidade, a honestidade, a lealdade, o zelo e a colaboração. Enfim, está presente, também na ambiência contratual, o sentido ético, a tendência socializante e a garantia de dignidade que são, por assim dizer, as marcas ou os marcos deste Direito que perpassando os séculos, se apresenta renovado, aos primórdios do milênio novo.' ${ }^{12}$

O art. 422 do novo Código estampa, precisamente, esse novo princípio, ao dizer que os contratantes são obrigados a guardar, assim na conclusão do contrato, como em sua execução, os principios de probidade e boa-fé. Mas estará seguramente melhor referido, o aludido princípio, se for aprovada a proposta de alteração do novo Código Civil, de autoria do deputado Ricardo Fiúza, o próprio relator do Código em sua fase final de tramitação, a qual, por meio do Projeto 6960/2002 (no momento aguardando parecer, na Câmara), sugere que o mencionado art. 422 passe a ter a seguinte redação: Os contratantes são obrigados a guardar, assim nas negociações preliminares e conclusão do contrato, como em sua execução e fase pós-contratual, os princípios de probidade e boa-fé e tudo mais que resulte da natureza do contrato, da lei, dos usos e das exigências da razão e da equidade.

A justificativa textual, apresentada no Projeto 6960/2002, menciona que a necessidade de se imprimir ao art. 422 esta nova redação, se dá pelo fato de a atual redação apresentar, conforme aponta o Desembargador Jones Figueiredo Alves, insuficiências e deficiências, na questão objetiva da boa-fé nos contratos. As principais insuficiências convergem às limitações fixadas (periodo da conclusão do contrato até a sua execução), não valorando a necessidade de aplicações da boa-fé às fases précontratual e pós-contratual, com a devida extensão do regramento.

Esta modificação de redação, ampliando significativamente os horizontes da regra da boa-fé objetiva nos contratos, é resultado, enfim, de um grande incômodo sentido pela comunidade jurídica brasileira, ao tempo da promulgação do Código, no que dizia respeito ao fato de não estar o dispositivo em comento, conforme a sua redação original, conectado com os momentos anteriores à formação do contrato - a fase précontratual - e nem mesmo os momentos posteriores à sua execução - a fase póscontratual. Em ambas as fases, deve estar presente, igualmente, o comportamento qualificado pela lealdade ou honestidade, considerando-se os interesses alheios, por força da celebração futura e execução posterior de um negócio jurídico.

Códigos alienígenas já consagram tais posturas mais ampliadas, como por exemplo, o Código Italiano que prescreve o dever daquele pré-contratante que perdendo o interesse no prosseguimento das tratativas preambulares e não mais desejando concluir o negócio, deva comunicar esta nova situação ao seu co-adjuvante

12. Estas considerações que se cncontram entre aspas simples, às ps. 07 c 08 desta transcrição, são as mesmas - cơm breves alterações ou supressões - que já haviam sido expendidas cm anterior palestra accrca das Tendências do Direito Civil no século XXI, proferida $\mathrm{cm} 21.09 .2001$, no Scminário Internaciona! de Dircito Civil, promovido pelo NAP - Núclco Acadêmico de Pesquisa da Faculdade Mineira de Dircito da PUC/MG 
pré-contratual, exatamente para liberá-lo do engessamento que é produzido pela obrigatoriedade da proposta negocial, permitindo que possa, ele, iniciar nova negociação conforme bem entenda, com o menor prejuizo possivel pela interrupção.

Da mesma maneira, a exigência de comportamento coerente com a boafé objetiva deve estar presente, também, nas hipóteses em que o contrato já se encontre terminado, pelo eventual cumprimento das obrigações dele resultantes. Haverá hipóteses em que tal conduta assim pautada deverá obrigatoriamente estar presente, sempre sob a perspectiva de minoração de prejuízos e incômodos ao outro contratante. A esse respeito, Junqueira de Azevedo, naquela palestra na Ouvidoria Parlamentar, já antes referida, mencionou o seguinte exemplo: na Alemanha, uma pessoa vendeu um terreno e disse ao comprador que, de lá, ele poderia ver o vale; assim, a situação topográfica do terreno se constituiria em uma vantagem do imóvel. Para justificar tal vantagem, o vendedor disse que o imóvel em frente a seu terreno, do outro lado da rua, não poderia receber edificações elevadas, pois haveria determinado limite para a construção. $A$ pessoa comprou o terreno e construiu uma casa, que, segundo a jurisprudência alemã, valia seis vezes o valor do terreno. O comprador estava muito satisfeito com essa situação, até que o mesmo vendedor comprou o terreno em frente, foi à Prefeitura, obteve licença para a mudança do projeto de zoneamento - de acordo com o nome que utilizamos - e construiu naquele local um edificio alto. Havia acabado a transação de compra e venda, caso em que, muitas vezes, o comprador nunca mais vê o vendedor. Porém, depois de terminado o contrato, ou seja, depois que vendeu, e o outro pagou, o vendedor comprou o imóvel em frente e, ele mesmo, prejudicou o antigo comprador. O fato caracteriza evidente falta de boa-fé.

Um exemplo assim - fato verdadeiro ocorrido na Alemanha, mas que certamente pode ocorrer, e ocorre, em nosso país, e todo momento - estava mesmo a revelar a urgência de se alterar o contexto do art. 422 do novo Código. Deve-se aguardar, portanto, a aprovação da nova redação, conforme o Projeto de Lei mencionado, de $n$. $6960 / 2002$. A regra, enfim, que corresponda, no colo positivo da lei, ao princípio da boa-fé objetiva não deve ser tida simplesmente como uma fonte de interpretação do contrato, mas deve ser tida, isso sim, pois é o que ela é, uma fonte de preenchimento de lacunas de cláusulas contratuais. Nem sempre é possível dizer, nas cláusulas dos contratos, toda a extensão das pretensões ali regulamentadas pelos contratantes. Aliás, pretender fazê-lo seria utópico, pois que se dá uma evidente impossibilidade natural e até física de se intentar esgotar as possibilidades, pela projeção já prevista em cláusulas. Ninguém pode fazê-lo. Mas a boa-fé objetiva, enquanto princípio fundador do Direito Contratual da atualidade, pode preencher a omissão. Provavelmente a nova redação sugerida pode conferir ao art. 422 um tal e desejável alcance.

Com relação ao princípio da função social do contrato, finalmente, encanta-me sempre mencioná-lo, assim como sempre me encanta pensar a função social da propriedade.

Este princípio vem consagrado - desde 1975, ano em que o Projeto 634 foi encaminhado à Presidência da República, para ser apreciado como o novo Código 
Civil Brasileiro - no atual art. 421 do novo Código. Em que pese o seu alto teor axiológico, e a alegria por verificar o legislador brasileiro reconhecendo a nova conotação social das relações privadas, é inegável, conforme apontam, com precisão, Junqueira de Azevedo e Álvaro Villaça Azevedo, que o dispositivo tem importantes defeitos que analisaremos a seguir, e que poderão igualmente ser corrigidos se a sugestão de alteração contida no Projeto 6.960/2002 for acolhida e aprovada, passando a ser a nova normativa brasileira acerca desse princípio agora sob exame, o da função social do contrato.

Mas antes, e apenas para não perder a oportunidade de tecer algumas considerações de caráter mais geral sobre essa limitação de ordem social imposta à esfera contratual, seria talvez útil considerar que a profunda repercussão social que o fenômeno da funcionalidade condicionadora - e, por isso, limitadora - do uso da propriedade foi que levou os pensadores e cientistas do Direito a compreender - e Duguit já havia feito essa previsão bem antes - que o atributo da função social não se encontra afeto apenas à propriedade, mas senão também ao contrato.

Orlando Gomes, o saudoso jurista de vanguarda, havia dito, logo nas primeiras considerações de seu clássico Transformações gerais do Direito das Obrigações, que se orienta modernamente o Direito das Obrigações no sentido de realizar melhor equilibrio social, imbuidos seus preceitos não somente da preocupação moral de impedir a exploração do fraco pelo forte, senão também, de sobrepor o interesse coletivo, em que se inclui a harmonia social. Para tanto, ele ponderava que se tratava, então, de submeter a ambiência contratual a um regime no qual a autonomia $d a$ vontade [estivesse] severamente restringida, o que acarretaria, seguramente - $\mathrm{e}$ sempre conforme a previsão de Orlando Gomes - enorme restrição de ocorrência de injúria contratual, a ponto de cercá-la de modo provavelmente absoluto.

A limitação contratual derivada da funcionalidade social se.instalaria no âmago do conteúdo contratual - e não exatamente, como é o meu sentir, no prenúncio da liberdade de contratar, domínio ainda perene da autonomia privada - de sorte a restringir a ingerência da vontade dos contratantes em áreas de salvaguarda social, de alcance inegavelmente mais dilatado.

Para compreender esse assunto, conviria apresentar a importante distinção entre dois aspectos da liberdade individual nos contratos, ainda hoje confundidos, inclusive pelo legislador brasileiro de 2002, conforme procurarei demonstrar, na seqüência. São dois lados de uma mesma moeda, por assim dizer, mas cada qual deles deve ser considerado de per si, em prol da verdadeira dimensão contratual, hoje. Refirome à distinção absoluta entre o que se convenciona denominar liberdade de contratar e liberdade contratual.

A liberdade de contratar ainda é aquela mesma liberdade facultada a todas as pesssoás de realizarem suas avenças, sem qualquer consideração sobre eventual restrição de conteúdo do contrato em foco, limitação essa que seja decorrente de uma determinada norma de ordem pública. Em outras palavras, a liberdade de contratar revela, exclusivamente, a liberdade que cada um tem de realizar contratos; ou de não 
os realizar, de acordo com a sua exclusiva vontade e necessidade. Por isso, é naturalmente ilimitada, uma tal liberdade.

Mas, diferentemente, põe-se a liberdade contratual, a qual, no dizer de Álvaro Villaça Azevedo, é considerada como a possibilidade de livre disposição de interesses, pelas partes, no negócio. ${ }^{13}$ Enfoca o conteúdo, ele mesmo, dos contratos, quer dizer, a sua consistência interna, traduzida pelas cláusulas que compõem o negócio. Este é o aspecto mais crítico da formação do contrato, uma vez que esta liberdade pode vir limitada por normas de ordem pública que digam qual o percurso cogente de determinadas cláusulas contratuais. Por isso, a liberdade há de condicionar-se emoldurando-se na lei, para ser liberdade condicionada, não ser liberdade-escravidão, instrumento dos que atuam de má-fé, em detrimento da própria sociedade, como mencionou, bem antes, Álvaro Villaça Azevedo.

Essa idéia dos limites impostos à liberdade contratual resulta do próprio fenômeno da publicização do Direito Privado, por meio, então, da interferência estatal nas relações havidas entre particulares, em atenção às exigências do bem comum e do interesse coletivo, num último passo. Não é difícil, portanto e como se vê, conceber que também o contrato, assim como a propriedade, possui uma função social que lhe é inerente, que o limita essencialmente, e que não pode, de modo nenhum, deixar de ser observada.

A função social - então, e enquanto princípio contratual - veio instalada, no bojo da novel legislação civil, em seu art. 421, o qual prescreve, em sua atual e original redação que a liberdade de contratar será exercida em razão e nos limites da função social do contrato. É fácil reconhecer, talvez, onde se assentam os dois enormes problemas desse dispositivo que precisa mesmo ser urgentemente modificado, para alcançar a perfeição de redação que permita se revela, em sua total consagração o referido princípio da função social.

\section{Vejamos, então, e para finalizar:}

Bem adverte Junqueira de Azevedo que a função social do contrato é um limite para a liberdade contratual, e efetivamente é. Não um limite à liberdade de contratar, como consideramos antes. E no que estaria fundada a liberdade de contratar, é a pergunta intrigante de Junqueira Azevedo, que respondeu a S. Exa., o professor Miguel Reale e a S. Exa., o deputado Ricardo Fiúza, naquele encontro na Ouvidoria Parlamentar, ao qual já me referi, antes, que no seu modo de ver - e lhe parece ser esse o pensamento implícito na Constituição Brasileira - baseia-se na dignidade da pessoa humana. No entanto - ele prossegue - esse artigo tem um viés trágico, porque determina textualmente que a liberdade de contratar será exercida em razão da função social.

Ora. Nem se trata de liberdade de contratar, nem deverá ser exercida em razão da função social do contrato.

$\mathrm{Na}$ verdade, trata-se de liberdade contratual, aquela pertinente à limitação do conteúdo do contrato, por força de norma de ordem pública, e não de liberdade de

13. Verbetc liberdade contratual, Enciclopédia Saraiva do Dircito 49/370-371, São Paulo: Saraiva, 1977. 
contratar, esta sim fundada na dignidade da pessoa humana e resultante da alta expressão da autonomia privada e, bem por isso, ilimitada.

Além disso, a liberdade contratual poderá encontrar, na função social que é inerente ao contrato, uma limitação à sua extensão meramente volitiva, uma vez que nem sempre os contratantes poderão, sem estes freios, fixar livremente as cláusulas de seu contrato.

E quando isso se der, quer dizer, quando certas cláusulas estiverem cogentemente registradas no contrato conforme a determinação de norma de ordem pública, se compreenderá, então, que a função social exerceu o seu verdadeiro papel, conforme convém. Exerceu o papel limitador da vontade dos contratantes, restringindolhes a liberdade contratual, e não qualquer outro papel que fosse delineado por um viés de fundamentação ou de razão de ser da própria restrição cometida.

Em desacerto, portanto, o mesmo art. 421, em dois momentos subseqüentes de sua composição legislativa, quando descreve que a liberdade de contratar' será exercida 'em razão' e no limite da função social do contrato. Insisto: a função social de que se cuida aqui, é função limitadora à fixação absolutamente livre do conteúdo contratual, mas não é fundamento para justificar ou sustentar a restrição imposta em certos casos. $e$

O Projeto n. 6.960/2002, atento a estas discussões - que não são recentes, mas que se encontram ressuscitadas, hoje, especialmente pela presença constitucional do mega-princípio da dignidade da pessoa humana e pela vasta tábua axiológica dada aos brasileiros e à sociedade brasileira como um todo - ostenta significativa alteração nesse art. 421, acolhendo, principalmente, a lição pontual e valorosa daqueles dois professores titulares de Direito Civil da Faculdade de Direito de onde venho para hoje, honradamente, estar aqui com V. Exas, digníssimos desembargadores e juízes do Estado de Minas Gerais. São eles - e já os referi antes - Antonio Junqueira de Azevedo e Álvaro Villaça Azevedo.

Se aprovado, enfim, o mencionado art. 421 , em exame, passará ele a ter a seguinte e muito mais precisa redação, permitindo ao juiz, se for o caso, o exame $a$ posteriori de eventuais nulidades contratuais decorrentes do desatendimento desse princípio, e não apenas o exame a priori, como ocorre à face do sistema geral das nulidades negociais: "A liberdade contratual será exercida nos limites da função social do contrato"

São Paulo, outubro de 2002. 